\title{
A Study of International Language and Culture Communication in China based on the Theory of Communication
}

\author{
Yanghua Peng \\ School of Foreign Languages \\ Chengdu College of Arts and Sciences \\ Chengdu, China \\ E-mail address: pengls@126.com
}

\begin{abstract}
A review of the current researches in the field of international language and culture communication in China has indicated that in the past decade both inheritance and creativity can be found in research content, yet emphasis is mostly put on ego rather than others in communication which poses itself as a problem. Under the direction of "the Belt and Road" Initiative, this paper tries to explore the international language and culture communication in China based on the theory of communication. This paper holds that it is vital and indispensable to try to integrate the theoretical basis of the concepts of "confidence in others" and "otherness" in the theory of communication into the international language and culture communication in China from the philosophical perspective. It is thus illustrated that the essence of the theory of communication reveals the essence of mankind and there is a high congruity between the two. Finally the paper believes that the theory of communication establishes a theoretical foundation to solve the problem.
\end{abstract}

Keywords-The theory of communication; International language and culture communication in China; Confidence in others; Ego; Otherness

\section{INTRODUCTION}

With the rapid development and great progress of the human society, Chinese Party Central Committee puts forwards "The Belt and Road" Initiative. To enlarge the crosscultural intercommunication of China and other countries, Chinese president $\mathrm{Xi}$ Jinping gave directions for it. Namely, "We will continue to draw on achievements of human civilization and learn from the foreign historical and referential experience while maintaining Chinese characteristics to impel the prosperity of the multi-civilization by mutual learning and mutual referencing." Under the direction of "the Belt and Road" Initiative, the studies of international language and culture communication in China have been research hotspots in recent years.

A review of the current researches in the field of international language and culture communication in China has indicated that in the past decade both inheritance and creativity can be found in research content, yet emphasis is mostly put on ego rather than others in communication which poses itself as a problem. Most of the researches focused on content of the translation in China's global communication and neglected the long-term grown of the Chinese traditional culture itself. They found their foot in "ego" and emphasized Cultural Exportation. The strong sense of ego would bring about the resistance and suspense even anxiety of the target audience inevitably [1]. Meanwhile there is few research about the acceptability of the target audience [2]. The international language and culture communication in China probably could be carried out from target audience's perspective when the counterparts getting to know the Chinese traditional culture [3]. To make a better exchange and communication of culture, it is of great necessity to get the otherness' feelings and needs [4]. Therefore the feature of single dimension in research perspective urges further study of theoretical basis of such concepts of "confidence in others" and "otherness". It is thus illustrated that the essence of the theory of communication reveals the essence of mankind and there is a high congruity between the two. Thus, the theory of communication establishes a theoretical foundation to solve the problem. It is argued that subjectivity and intersubjectivity form necessary enlightenment for the concept of "confidence in others" and the relationship between "otherness" and "ego" in international language and culture communication in China.

\section{THEORY OF COMMUNICATION AND INTER-SUBJECTIVITY}

The application of the theory of communication to international language and culture communication in China is not based on a fancy but found on an implementation of the Basic Principles of Marxism especially human's subjectivity and the theory inter-subjectivity proposed by Juergen Habermas, currently ranks as one of the most influential philosophers in the world.

\section{A. Theory of Communication}

In the book of German Ideology, Karl Marx put forward that communication refers to the material and spirit intercourse not only between individual and association but also between nations and countries. Language and culture along with communication originated from the interaction of man's the material and spirit intercourse. Men, developing their material production and their material intercourse, alter, along with their real existence, their thinking and the product 
of their collective thinking. Communication has been developed into a hot issue in the field of western philosophy and sociology from the common word of daily life. Simultaneously, it will be on the way towards publicity of thoughts, internationality of politics and integration of disciplines [5]. The international language and culture communication in China pushes forward the development and expansion of communication in human society, which reflects the reinforcement of human's subjectivity. Many western philosophers such as Montesquieu, Kang De, Hegel, Marx and Habermas discoursed the key terms of communication from different perspective. Among them, the idea of Marx and Habermas is the most influential and remarkable, which guiding the international language and culture communication in China. The words of subjectivity, relationship, interaction, ego and otherness are the key terms of communication through sorting their ideas. It is found that these concepts tend to transform subjectivity to inter-subjectivity.

Also Marx revealed the essence of human nature: subjectivity and communication. On the one hand, human can change the surroundings to adopt the environments and they can produce their means of subsistence according to their own needs. On the other hand, man cannot exist without the environments deepened on. They are not isolated but involved in the society. They are the total complex of human relations. The sociality and communication becomes striking apparently in today's society, which lead to a new challenging problem to the international language and culture communication in China.

\section{B. Inter-subjectivity}

The inherent characteristics of inter-subjectivity determines the expansion of relationship between the subjects. With the rapid development of inter-subjectivity, the communication of subjects developed into international communication. The value orientation of freedom, equality and responsibility are established accordingly in the developed market economy. With the global problems occurring, the consciousness of peaceful coexistence of nations upsurge in today's society. The way of communication is of course a good choice to keep the sustained, stable and coordinated development balance of human world.

\section{THE INTERNATIONAL LANGUAGE AND CULTURE COMMUNICATION}

The international language and culture communication in China refers to the cross-culture exchange and communication between the other countries and regions. It includes not only the spreading of Chinese traditional culture but also the activities between Chinese culture and the otherness' culture (Hou $\mathrm{Xu}, 2018$ ). The practice of the international language and culture communication in China can be traced back to the ancient times. In the century of 3BC, the Southern terrestrial Silk Road opened. Afterwards, the maritime routes greatly promoted the development and progress of the international language and culture communication in China.

\section{A. Current research situation}

There are many relevant researches into the international language and culture communication in China. Inheritance and creativity can be found in these researches. Researches on country in Southeast Asia [6] aim to take history as a mirror and accelerate the intercommunication of culture. The object country of researches from the Southeast Asia to Central Asia such as a history review of the culture melting between China and Central Asia in Han and Tang Dynasty [7]; and an introduction of culture communication between China and Central Asia [8]. Furthermore, introductions and some strategies to Chinese language spreading can be found in the content, which displays the creativity of research into the international language and culture communication in China. Researches of reviews on the spreading of Chinese language in Southeast Asia points out that some problems about the mode of independent research and teaching planning and so on [9]. Some issues on culture integration about Chinese popularization are also discussed [10]. The characteristics of creativity also embodied in the probe of the theory of crosscultural communication. Some basic theories about cultural communication of the relationship between culture and communication, the communicative relationship between people are also illuminated as well [11]. Li Jianjun [12] analyzed the problem of the constructing Chinese cultural communicative force from the four aspects of the otherness, cooperation, conversation and presence and so on.

Researches mentioned above shows that the feature of single dimension in research perspective, which urges further study of theoretical basis of such concepts of "confidence in others" and "otherness". Scholars indicates that the tendency of single dimension in cross-cultural communication can be avoided through constructing a mode of win-win cooperation followed by principle of equal communication. Simultaneously, the otherness is an indispensable part while constructing the mode and otherness contributes to the mutual communication of the fine cultural heritage of their nation. Thus, the defect of powerful publicity and overweighed single cultural exportation can be overcome appropriately. 


\section{B. Solving the single dimension in intercommunication}

Stuart Hall, a master of Contemporary Cultural Studies, holds that the cultural communication is the core of culture and the laws and disciplines of development of culture can be perceived only by means of communication. If people take culture as something of priori knowledge, cultural understanding and acceptability will be unilateral and rigid, which of course will be an obstacle to the intercommunication. Intercommunication is the key of constructing the universal ethical principle no matter in homogeneous or heterogeneous culture. As mentioned previously, human as a total complex of communication is in the first place and the essence of human communication is the essential attribute of cultural communication. In view of this, international language and culture communication originates from intercommunication in itself and reciprocity combines them both.

Meanwhile confidence in others is a capability of trusting others. It plays a significant role in constructing the mode of international language and culture communication in China. The international language and culture communication in China contains both go-global strategy of Chinese traditional culture and come-in of the fine cultural heritage of others' nation. The two-way communication and mutual needs are founded on the self-confidence of our national culture and confidence in others of others' culture. The respect of man's subjectivity established on the thoughts of communication provides theoretical basis for constructing the confidence in others. As people is the sum of communication, the essence of communication should be people oriented. Namely people is the subject and thus people's actual feeling and needs should be taken into consideration. The intrinsic quality of cultural communication determines the role of people in its construction and development. Cultural communication is not single dimension but bidirectional way. In this way, international language and culture communication turns to be ecological system including human beings and environment. Human being is communicator and communicatee as well. Environment involves the international society and surroundings where communicator and communicatee communicate. The ecological system in which international language and culture communication occurs should be associated and interactive.

Specifically, in the practice of international language and culture communication, communicator will pay attention to the psychological acitivity of the communicatee, the needs of personal emotion, sympathy of thoughts, characteristics of culture of their nation and so on. These needs is the demonstration of confidence in others in the international language and culture communication. The communication of single dimension of ego neglects the high-level emotional needs. In the process of intercommunication, mutual understanding, spiritual awaking, emotional experiencing, and equal conversation must promote international language and culture communication and make up for a deficiency the communication of single dimension of ego. The relationship between otherness and ego transforms from the pattern of subject-object into the mode of subject-subject. Otherness are endowed with the subjectivity. It is admitted that ego and otherness coexists in the common ecological system. It is obviously that the two counterpart of communication are the subjects. They both equally are on the side of others when communicating. Followed by this way, the mutual mental needs may be meets and mutual understanding and confidence in each other may take place naturally. Consequently, the purpose of international language and culture communication is not only to make the world get to know China but also to accelerate the intercultural communication guided by the theory of inter-subjectivity, which is consistent with the goal of "the Belt and Road" Initiative.

\section{CONCLUSION}

“The Belt and Road" Initiative bring new chances and challenges for the international language and culture communication in China. Scholars are confronted with the problems of intercommunication of single dimension in research perspective. The concepts of "confidence in others" and "otherness" in the theory of communication reveals the essence of communication, which is consistent with the essence of mankind and there is a high congruity between the two. Under the direction of the theory of communication, the double subjects between communicator and communicatee should be concerned in the field of international language and cross-cultural communication. The thoughts of intersubjectivity and theory of communication provide a new angle for the study of international language and culture communication in China. Eventually, further study can be probe into the problems confronted in practice of international language and culture communication in China based on the theory communication and more specific strategies to the discourse right of communication between the two subjects.

\section{ACKNOWLEDGMENT}

I would like to take this opportunity to thank all those who have given me much help in my studies and work.

First and foremost, I am greatly indebted to my supervisor, Professor Wang Weimin, for his enlightening advice, scholarly inspiration and continuous encouragement. Without his guidance, the completion of this article would have been impossible. Appreciation is also expressed to him for always being kind, understanding, and helpful during the undertaking of my life.

I would also like to express my heartfelt gratitude to all the outstanding professors in the School of Foreign Languages of Southwest Jiaotong University, from whom I have benefited a lot in the three-year graduate studies. Special thanks go to Professor Fu Yonglin for his illuminating suggestions on my work and lectures in the translation course.

My thanks also go to my former colleague and friend, Liu Zhenning, for his help and guidance in my academic studies, and to my colleague and schoolmate, Wan Jiangsong, for his valuable suggestions and careful proofreading.

Last but not least, I am also grateful to my family for their timely encouragement and considerable care. 


\section{REFERENCES}

[1] Li Jianjun, “An Construction of Cultural Communication between China and Central Asia" Journal of South-central University for Nationality, 2013. (In Chinese)

[2] Guo Lihua. "A Report on the Audience's Psychology and Communication" Modern Media, 2010. (In Chinese)

[3] Zhang Kun. "National-image Oriented Cultural Exportation and Communication". Today's Media, 2005. (In Chinese)

[4] Hou $\mathrm{Xu}$. "A new research on international language and culture communication in China Under the direction of "the Belt and Road" Initiative ". Journal of Xian International Studies University, 2018. (In Chinese)

[5] Cao Weidong. "Communication" Reading, 1995. (In Chinese)

[6] Zhang Chengxia, Luo Jinmin. Chinese Influence on the culture of Southeast Asia. 2014. (In Chinese)

[7] Dai Xiaojiang. The Influence of Chinese Culture on the Central Asia. Jurnal of Heze Normal Institute. 2004. (In Chinese)

[8] Xu Ercai. "Cultural Communication between China and Central Asia" Journal of Xin Jiang University., 2012. (In Chinese)

[9] Luo Ji, Qian Rui. "A Historical research on the Chinese Communication of Southeast Asia: Current Situation and Reflection" Journal of Yun Nan Normal University, 2014. (In Chinese)

[10] Fan Rong. "A Study on the Issue of Language Popularization and Culture Integration”. Northeast University. 2012. (In Chinese)

[11] Shan Bo. "The Basic Issue of Cross-culture Communication". Journal of Central China Normal University. 2011. (In Chinese) 